\title{
EL PLIEGO POÉTICO INCUNABLE 90DC: MATERIALIDAD Y ADSCRIPCIÓN TIPOGRAFICA*
}

\author{
Juan Francisco Mesa Sanz \\ Universitat d'Alacant \\ juan.mesa@ua.es
}

\section{Introducción y objetivo}

«Es de catón» sigue siendo en la actualidad un adagio empleado con el significado de que responde a una norma asimilada por todos, que llegó hasta nuestros días en su forma de cartilla escolar ${ }^{1}$. Ambos hechos, la frase estereotipada y la existencia en el siglo xx de la obra citada, indican el éxito y popularidad que alcanzaron los Disticha Catonis desde su lejana redacción en el siglo IV d. C. hasta la edición erasmiana de $1513^{2}$, cuyos comentarios y esfuerzo por la fijación textual lo convirtió en el texto canónico hasta la monumental edición crítica de $\mathrm{M}$. Boas ${ }^{3}$, cuyo aparato crítico fue calificado por

\footnotetext{
${ }^{*}$ Este trabajo se enmarca dentro del proyecto Cancionero, romancero y fuentes impresas, del Ministerio de Economía, Industria y Competitividad (FFI2017-86313-P), financiado por la Agencia Estatal de Investigación (AEI) y el Fondo Europeo de Desarrollo Regional (FEDER/UE), cuyo investigador principal es Josep Lluís Martos.

${ }^{1}$ Catón moderno, Barcelona, Editorial F.T.D., 1922 (existe una reimpresión facsímil: Barcelona, Editorial Luis Vives (RBA), 2007).

${ }^{2}$ A. García Masegosa, Erasmo de Rotterdam. «Los dísticos de Catón comentados», Vigo, Servicio de Publicaciones de la Universidad de Vigo, 1997. No obstante, el 23 de marzo de 1491 Andrés Gutiérrez de Cerezo (c. 1459-1503), discípulo de Nebrija en Salamanca hacia 1479, había publicado en Venecia los Libri minores que incluían los Disticha Catonis, De contemptu mundi, las Fábulas de Esopo, un Floretus, y el Liber quinque clavium sapientiae; esta edición tuvo enorme éxito hasta el punto de ser revisada y anotada por el propio Antonio de Nebrija, consolidándose dicha edición en la publicación de Granada (1534) de la que se realizaron numerosas ediciones posteriores (A. de Nebrija, Libri minores, ed. de Marco A. Gutiérrez, Salamanca, Ediciones Universidad de Salamanca, 2009). Tan solo el número de ediciones realizadas es una muestra evidente del interés de esta obra de carácter propedéutico y escolar.

${ }^{3}$ Marcus Boas, Disticha Catonis, recensuit et apparatu instruxit, opus post Marci Boas mortem edendum curauit Henricus Johannes Botschuyver, Amsterdam, North-Holland Publishing Co., 1952. M. Boas
} 
L. Bieler como «the fuller I have ever seen» ${ }^{4}$. En efecto, este es extraordinariamente complejo, puesto que expone las variantes de los manuscritos y los incunables, así como las conjeturas de los editores; añade Exempla et Fontes, Laudationes et Imitationes; y, por último, en aquellos pasajes que considera especialmente problemáticos, una sección que etiqueta como Notabilia o Memorabilia, según sea el caso. Obviamente, entre los numerosos testimonios conservados, M. Boas se vio en la obligación de realizar una selección; y ésta respondió al criterio de mostrar las diferentes etapas de la tradición textual de los Disticha Catonis, más que al de ilustrar las diversas ramas del stemma codicum. De hecho, por ejemplo, el propio M. Boas ${ }^{5}$, pero mucho más H. J. Botschuyver ${ }^{6}$, manifiesta sus dudas sobre la hipótesis de la existencia de una familia hispano-gálica del texto. Por ello, pese a las indudables virtudes de esta edición crítica, la abundancia de testimonios y la decisión de primar las citadas etapas de la tradición y no las posibles filiaciones de los testimonios, entre otros aspectos, contribuyen al hecho de que la investigación textual de los Disticha Catonis no puede considerarse concluida; valga en este sentido el ejemplo de la mencionada familia hispano-gálica, hipótesis recuperada por Tomás González Rolán al analizar la posición del manuscrito Ripollensis 106 en esta tradición textual ${ }^{7}$.

Los Disticha Catonis, a pesar de las familias textuales y las diferencias entre ellas, está compuesto en todos los casos por cuatro libros que agrupan respectivamente 40, 31, 24 y 49 dísticos y monósticos; los libros II, III y IV pueden presentar breves prólogos en hexámetros, mientras que el primero está precedido por una carta a modo de prólogo que el autor dirige a su hijo, ya que afirma que el libro ha sido compuesto para su educación ${ }^{8}$ y que cierra con una serie de 56 praecepta. Se trata, en suma, de un prólogo que afecta a

no pudo concluir su edición, comenzada en 1906 (Paul van de Woestijne, «Reseña» a Boas, ob. cit., en L'antiquité classique, 22 (1953), pp. 183-184), debido a su fallecimiento en 1941; conservado su manuscrito y los materiales que había trabajado en la Biblioteca de la Universidad de Amsterdam, la edición pudo ser culminada en 1952 por H. J. Botschuyver.

${ }^{4}$ L. Bieler, «Reseña» a Boas, ob. cit., en Scriptorium 9:1 (1955), pp. 154-155, p. 155.

${ }^{5}$ Boas, ob. cit., pp. XLIX-LX.

${ }^{6}$ Ibidem, pp. XLVI y ss.

${ }^{7}$ «Pero lo mismo Baehrens tampoco M. Boas se percató de la existencia del manuscrito de Ripoll, aunque ya R. Beer en 1908 había dado referencias de él», Tomás González Rolán, «La tradición de los Dicta Catonis y el Ripollensis 106», en Habis, 5 (1974), pp. 93-108, p. 102, manuscrito que se convierte en un testimonio importantísimo dentro de la familia hispano-gálica de la Vulgata.

${ }^{8}$ Se trata de un tópico frecuente en la literatura sapiencial, consagrado en la literatura latina desde Catón el Censor, quien dedica De agricultura a su hijo; no obstante, pese a lo que pudiera parecer es un tópico no exento de realidad como, ya en el siglo v d.C., puede verse en el prólogo epistolar de las mismas características realizado por Macrobio en Saturnales (Macrobio, Saturnales, intr. y trad. Juan Francisco Mesa Sanz, Madrid, Akal, 2009). 
la obra en su conjunto y no sólo al libro I, y que establece los parámetros del éxito de los Disticha Catonis, en la medida en que suponen una herramienta educativa que aúna el aprendizaje gramatical básico y la formación moral de los pupilos.

Dicho éxito y el objeto para el que fue concebido propició la aparición desde muy pronto de variantes, adiciones, modificaciones, así como su inclusión en numerosos manuscritos - y posteriormente impresos- facticios que, como se ha apuntado arriba, contribuyen a una compleja historia del texto latino que ha de ser todavía completada con nuevas investigaciones. Ahora bien, la historia del texto no podrá concluirse si se excluye en la reconstrucción el estudio de las traducciones, muchas de las cuales incluyen el propio texto latino, y de las que «los trabajos críticos sobre las mismas siguen siendo muy pocos» $\rangle^{9}$.

Como ha señalado Elena González-Blanco, «existen pocas ediciones y pocos estudios que se hayan ocupado en profundidad del análisis de su trascendencia» [de las traducciones castellanas de los Disticha $]^{10}$. La autora citada subraya que la mayoría de los textos conservados lo hacen por medio de copias del siglo Xv, antes de proceder a la exposición de cada una de las traducciones localizadas. Son las siguientes:

a) Castigos y exemplos de Caton: datada a finales del XIII o comienzos del XIV. Realizada en cuaderna vía. El dato más relevante es que ninguno de los tres manuscritos referidos por González-Blanco contiene el texto en su totalidad, sino que éste aparece en pliegos sueltos, en los nueve textos impresos ${ }^{11}$

\footnotetext{
${ }^{9}$ Elena González-Blanco García, «Las traducciones romances de los Disticha Catonis», en eHumanista, 9 (2007), pp. 20-82, p. 24. De hecho, es significativo el incremento de trabajos sobre los Disticha que se registran desde la última década del siglo xx: Pierre Civil, «La formation à travers les Catones», en Agustín Redondo, La formation de l'enfant en Espagne aux XVI $I^{e}$ et XVII ${ }^{e}$ siècles, París, Publications de La Sorbonne, 1996, pp. 254-271; Hugo O. Bizarri, «Algunos aspectos de la difusión de los Disticha Catonis en Castilla durante la Edad Media (I)», en Medioevo Romanzo, 26:1 (2002), pp. 127-148; Francisco Gago Jover, Textos y concordancias de las versiones castellanas de «Disticha Catonis», New York, Hispanic Seminary of Medieval Studies, 2003; Juan Francisco Sánchez López, La ética de Catón. Martín García Puyazuelo, Zaragoza, Prensas Universitarias de Zaragoza, 2009; Elena González-Blanco García, El «Catón» en la literatura europea, versiones, antología de textos y bibliografia comentada, Saarbrücken, Editorial Academia Española-Lap Lambert Academic Publishing GmbH \& Co. KG, 2012.

${ }^{10}$ Elena González-Blanco García, «Las traducciones romances...», art. cit., p. 32. Es la misma denuncia que Víctor Infantes, «El Catón hispánico: versiones, ediciones y transmisiones», en Lucía Megías, José Manuel (ed.), en Actas del VI Congreso Internacional de la Asociación Hispánica de Literatura Medieval (Alcalá de Henares, 12-16 de septiembre de 1995), Alcalá de Henares, Universidad de Alcalá, 1997, tomo II, pp. 839-846, realiza tanto para el texto latino de los Disticha Catonis, como en las versiones en lenguas romances peninsulares.

${ }^{11}$ Antonio Rodríguez Moñino, Nuevo Diccionario Bibliográfico de Pliegos Sueltos Poéticos (s. XVI), Madrid, Castalia, 1997.
} 
que arrancan en el ejemplar perdido que fue posesión de Hernando de Colón ${ }^{12}$.

b) La traslation del muy excellente doctor chaton ${ }^{13}$ : una nueva versión en redondillas fue realizada por Martín García Puyazuelo a mediados del siglo $\mathrm{XV}$, bajo el epígrafe de «La traslation del muy excellente doctor Chaton». El texto se conserva en una única edición conocida, sin lugar ni fecha, pero seguramente compuesta en Zaragoza hacia 1490. Según nos describe Pérez y Gómez (1964) ${ }^{14}$, Martín García era aragonés, procedente de Caspe y durante su vida desempeñó cargos religiosos que le llevaron a Roma y Barcelona, donde rigió la diócesis hasta 1519, fecha en que se retiró a su ciudad natal, en la que falleció dos años más tarde. Afortunadamente es el propio autor quien en el texto se ocupa de señalar que terminó la obra en 1467, aunque se imprimiera algunos años más tarde.

c) El Catón en latín \& romance [...] vulgarmente llamado el catón: traducción en coplas de arte mayor de Gonzalo García de Santa María, fechada y editada hacia 1493. La datación procede del propio traductor quien afirma que ha realizado este trabajo por encargo del impresor Pablo Hurus en el verano de $1493 \mathrm{y}$, por ello, existe unanimidad en aceptar esta fecha para la impresión (o quizá 1494) en dicha imprenta, lo que ya publicó $\mathrm{Neve}^{15}$.

d) Disticha de moribus, nomine Catonis inscripta: traducción en prosa de Martín Godoy de Loaisa ${ }^{16}$, cuya reedición en seis ocasiones en un periodo de 20 años habla de su éxito ${ }^{17}$.

Hemos trasladado las palabras de González-Blanco en su totalidad en lo relativo a la segunda de las traducciones mencionadas, puesto que constituirá

\footnotetext{
${ }^{12}$ González-Blanco García, «Las traducciones romances...», art. cit., p. 33.

${ }^{13}$ González-Blanco García, «Las traducciones romances...», art. cit., p. 34.

${ }^{14} \mathrm{~A}$. Pérez y Gómez, Versiones castellanas del Pseudo Catón, Noticias bibliográficas, Valencia, Artes Gráficas Soler, 1964.

${ }^{15} \mathrm{~J}$. Nève, Catonis Disticha. Facsimilés, notes, liste des éditions $d u X V^{e}$ siècle, Paris, H. Vaillant-Carmanne, 1926. La obra se conserva gracias a un único ejemplar conservado en la Biblioteca Nacional que describió y transcribió, y trasladó a un facsímil Pérez y Gómez, Antonio, Incunables poéticos castellanos IX, Valencia, 1964, existiendo muchas lagunas acerca de la biografía del traductor.

${ }^{16}$ Martin Loaisa, ed., Disticha de moribus, nomine Catonis inscripta, cum Latina \& Hispanica interpretatione, Lyon, Jean \& François Frellon, 1543.

${ }^{17}$ González-Blanco García, «Las traducciones romances...», art. cit., p. 35. La autora (pp. 35-36) refiere dos traducciones más, ambas del siglo XVIII, con gran impacto en el panorama literario español: Gabriel Rodríguez (1732) y León de Arroyal (1797).
} 
el objeto de nuestro trabajo. Se trata del incunable conocido como 90DC descrito por Carlos Alvar y José Manuel Lucía Megías del modo siguiente ${ }^{18}$ :

[C] Traducción completa de Martín García, compuesta en redondillas de arte menor en 1467 e impresa con el texto latino, sin nombre, sin lugar, sin año. Se han propuesto posibles pies de imprenta de Toulouse: Henricus Mayer, ca. 1490 y Zaragoza, ca. 1500. No se conoce ningún manuscrito. Editado por Clavería (1989).

El Corpus de Incunables de Clásicos Latinos en España (CICLE 0118) subraya justamente la incertidumbre sobre el impresor, denominado genéricamente «Impresor del Catón» (TW of1580) o bien el citado arriba Heinrich Mayer (TW of0183) de Toulouse ${ }^{19}$. Paradójicamente, puesto que no hay ninguna razón aparentemente esgrimida, en el Typenrepertorium der Wiegendrucke ${ }^{20}$ se establece una relación directa entre la identificación del impresor y la data. Decimos que es paradójico, porque, si bien la identificación con la imprenta tolosana de Mayer permite una mayor acotación temporal, la identificación con una imprenta zaragozana no identificada, que lleva la data a 1500 sin que se aduzcan las razones, se amolda mejor a la biografía de Martín García ${ }^{21}$. Asimismo, hay otro aspecto sobre el que llamar la atención: los tipos se han identificado con $1: 115 \mathrm{G}$ y $2: 115 \mathrm{G}$, tal como aparece también en

${ }^{18}$ Carlos Alvar y José Manuel Lucía Megías, Diccionario filológico de literatura medieval española. Textos y transmisión, Castalia, Madrid, 2002, p. 247. Existe una edición facsímil: Antonio Pérez y Gómez, Incunables poéticos castellanos, III, Valencia, 1954; y una transcripción, de Carlos Clavería, «La traslaçion del muy excelente doctor Catón llamado, hecha por un egregio maestro, Martín García llamado», en Cuadernos de Estudios Caspolinos, xv (1989), pp. 29-140.

${ }^{19}$ CICLE, Corpus de Incunables de Clásicos Latinos en España. [En línea]. Enlace: <http://www. incunabula.uned.es/cicle.php> [Consulta: 30/01/2020].

${ }^{20}$ Typenrepertorium der Wiegendrucke. [En línea]. Enlace: <https://tw.staatsbibliothek-berlin.de/ of1580 y https://tw.staatsbibliothek-berlin.de/of0183> [Consulta: 30/01/2020].

${ }^{21}$ Nacido aproximadamente en 1441 , se traslado a Zaragoza entre 1452 y 1454 para realizar estudios de sacerdote. De 1476 a 1480 realizó estudios en el Colegio de San Clemente de los Españoles de Bolonia con una de las tres becas que correspondían a la Corona de Aragón, regresando a Zaragoza el mismo año de 1480. Su carrera fue en continuo ascenso hasta alcanzar su punto culminante, tras el asesinato de Pedro Arbués, dándole un impulso definitivo a la implantación de la Inquisición en la Corona de Aragón. Gracias a su participación fue nombrado el 31 de octubre de 1485 vicario general del arzobispo para entender asuntos de la Inquisición y en 1487 Predicador oficial del rey; arcediano de Daroca en 1493, cargo que no exigía desplazarse a dicha población. En 1512, mientras se encontraba de embajada en Roma, fue nombrado obispo de Barcelona, ciudad en la que entró en función de su cargo en 1515. En 1519 se retiró a Caspe, donde murió en 1521 (véase Juan Francisco Sánchez López, Martín García Puyazuelo. La ética de Catón, Zaragoza, Larumbe-Prensas Universitarias de Zaragoza, 2009, pp. XI-Xxiv; y M. Montoza Coca, Los Sermones de Don Martín García, obispo de Barcelona. Edición y estudio, tesis doctoral, Barcelona, Universitat Autònoma de Barcelona, 2018, pp. XV-XVIII). 
el Gesamtkatalog der Wiegendrucke ${ }^{22}$ (GW 06384), de modo que únicamente concuerdan con el denominado «Impresor del Catón». De hecho, Haebler (BI $289)^{23}$ observa:

GARCÍA, MARTIN. Traslación del muv excelente doctor chatón. - sin indicaciones tipográficas. $-4^{\circ}$. - 48 hjs no fols. - sign: A-F3. - letra gótica de dos tamaños.

El E. P, Fr. Benigno Fernandez en los artículos que lia consagrado álos incunables de la Biblioteca del Escorial trae este libro con la nota: Zaragoza, á finos del siglo xv? lié visto otro ejemplar existente en la Bibl. de la R, Academia Española, pero disiento del docto bibliotecario Escurialense en lo que se refiere al origen del libro, que está impreso con un tipo desconocido entre los de los incunables de España. Creo que pertenece al siglo XVI.

El ISTC, por su parte, resuelve esta paradoja afirmando que «The types are perhaps those of Mayer»; o, lo que es lo mismo, se está apuntando a que no existe identificación plena, sino una relación de semejanza entre los tipos del «Impresor del Catón» y los de Heinrich Mayer. Francisco Vindel ${ }^{24}$, no obstante, pone esta obra en relación con la Expositio super summulis Petri Hispani de Juan Versor a partir de la tipografía a dos tamaños, cuyas mayúsculas facsimila en su catálogo:

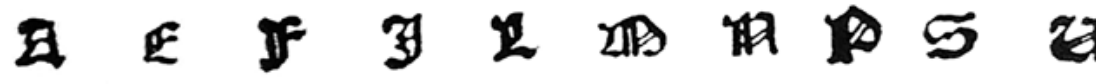

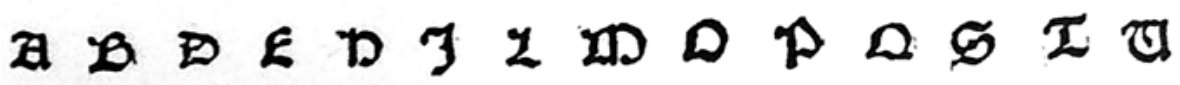

${ }^{22}$ Gesamtkatalog der Wiegendrucke. [En línea]. Enlace: <https://www.gesamtkatalogderwiegendrucke.de/docs/GW06384.htm> [Consulta: 30/01/2020], que ofrece las siguientes referencias de catálogo: Haebler 140.5. 289 (K. Haebler, Bibliografía ibérica del siglo XV. Enumeración de todos los libros impresos en España y Portugal hasta el año de 1500, La Haya-Leipzig, Martinus Nijhoff-K. W. Hiersemann, 1903); Vindel: Arte tip. VIII 38.11 (Francisco Vindel, El arte tipográfico en España durante el siglo XV. Dudosos de lugar de impresión, adiciones y correcciones a toda la obra, Madrid, 1951, pp. 38-40); Sanchez 78; IBE 1535 (Francisco García Craviotto, Catálogo General de Incunables en las Bibliotecas Españolas, 2 vols., Madrid, Biblioteca Nacional, 1989-1990); ISTC ic00319950 (Incunabula Short Title Catalogue, British Library. [En línea]. Enlace: <https://data.cerl.org/istc/ic00319950> [Consulta: 31/01/2020].

${ }^{23}$ Y no BI140 como figura en algunos catálogos; 140 (5), como ya señaló Vindel (ob. cit., p. XXVIII), corresponde a la segunda parte de la obra de Haebler (Haebler, Konrad, Bibliografia ibérica del siglo XV. Segunda parte, Leipzig-La Haya, Hiersemann-Martinus Nijhoff, 1917) y, en palabras del citado Vindel, «se contradice notablemente, diciendo: No había incluido este libro en mi "Bibliografía ibérica" del siglo $X V$, aunque lo conocía muy bien y había estudiado muy a fondo el ejemplar».

${ }^{24}$ Ibidem, p. XXVIII. 
Fruto de esta comparación, Vindel corrigió la adscripción errónea que se había realizado de la segunda de las obras a Sevilla hacia 1480 y, sobre todo, en lo que nos concierne, que «ambas obras son estampaciones de un taller desconocido en nuestra Península hacia 1490».

En consecuencia, el exhaustivo análisis del estado de la cuestión en torno a 90DC, revela algunas de las incógnitas todavía por resolver: en primer lugar, la identificación del impresor y, en consonancia con ello, del lugar de impresión, toda vez que, pese a la persistencia en la figura de Heinrich Mayer ${ }^{25}$, todo apunta a que no es el impresor, pero queda por dilucidar si se trata de un taller zaragozano ${ }^{26} \mathrm{o}$ de otro peninsular; y en segundo lugar, la datación, que se ubica mayoritariamente en una horquilla que va desde 1490, más o menos, hasta 1500 de un modo genérico ${ }^{27}$.

Otro aspecto adicional es que se cita en todas las ocasiones la existencia de tres ejemplares conservados de esta edición: Zaragoza (Universidad), El

${ }^{25}$ La Biblioteca Universitaria de Zaragoza dispone en sus fondos de un impreso atribuido sin duda a este taller, Expositio Hymnorum (BUZar I 279-5), que forma parte de un facticio en el que le preceden, además de un interesantísimo manuscrito, Esopo, Pamphilus, Disticha Catonis y Dato. Volveremos sobre este ejemplar al tratar de la tipografía.

${ }^{26}$ En este sentido apuntan Juan Manuel Sánchez, Bibliografia zaragozana del siglo XV, Zaragoza, 1905 , n. ${ }^{\circ} 78$, n. 79 y Luis Romero Tobar, «Los libros poéticos impresos en los talleres de Juan y Pablo Hurus», en Aragón en la Edad Media, 8 (1989), pp. 561-574. Este último señala a Martín García dentro del grupo de los colaboradores de Hurus junto a Gonzalo García de Santa María, Andrés Li, fray Gauberte Fabricio de Vagad o Mosén Martín Martínez de Ampiés (ibidem, p. 564), hasta el punto de incluir 90DC en la nómica de «libros estrictamente poéticos salidos del taller de los Hurus» (ibidem, p. 570; en n. 38 señala que «Una anotación manuscrita en el Catálogo Colectivo de Incunables de la Biblioteca de la Universidad de Zaragoza lo atribuye a la imprenta de Henricus Meyer, Toulouse, c. 1490»), lo que le permite concluir: «Los libros impresos de poesía de autores aragoneses que publica Pablo Hurus conforman sendos repertorios de enseñanzas morales y de consideraciones devotas: dos direcciones frecuentadas por muchos escritores aragoneses de todos los tiempos y que, en los años finales del xv, tienen sus representantes en Gonzalo García de Santa María, Martín García y Martín Martínez de Ampiés. Los Catones de los dos primeros y el Triumpho de María del tercero constituyen aportaciones a la poesía didáctica y religiosa de finales del xv cuyo marco de referencia es el de los géneros líricos vigentes en la poesía peninsular del momento, pero cuyos referentes inmediatos están situados en el ambiente intelectual que rodea a la imprenta zaragozana de los hermanos Hurus» (ibidem, p. 574).

${ }^{27}$ Erróneamente, algunos trabajos atribuyen a Dutton la posible fecha de 1477. Sin embargo, Brian Dutton, El cancionero del siglo XV (1360-1520), 7 vols., Salamanca-Universidad de Salamanca, 19901991, V.12 [ID6940 I 6941 y ID6942] fecha la impresión en 1490?; la fecha de 1477 corresponde a la que Dutton considera de redacción, y que realmente ha de ser 1467, tal como refiere el propio Martín García al final de su obra (vv. 1697-1770 ), ed. Sánchez López, ob. cit., p. 132: El presente ya se qüenta / del divino nacimiento / mil et siete con sesenta / et más quatre fazen ciento. Igualmente Dutton divide en tres piezas diferentes, 90DC-1, 90DC-2 y 90DC-3: las dos primeras constituyen realmente partes de una misma obra: introducción (90DC-1), tratado y colofón (90DC-2, donde, además, se incluye el título y la fecha de composición); la tercera, integrante del mismo incunable, incluye las Coplas a Nuestro Señor de Martín García (Juan Francisco Sánchez López, «Edición anotada y estudio preliminar de las Coplas a Nuestro Señor, de Martín García Puyazuelo», en Anuario de Centro de la UNED en Calatayud, VII:1 (1999), pp. 219-233 [=Cuadernos de Estudios Caspolinos, 24 (1999), pp. 145-168)] compuesta por «23 coplas de arte menor en las que se describe la pasión y muerte de Cristo» (Sánchez López, La ética ..., ob. cit., p. XCVII). 
Escorial y Madrid (RAE). De ellos, sólo se indica la imperfección del último y la bibliografía ha atendido sobre todo al primero ${ }^{28}$. Se hace necesario, por tanto, proceder al análisis material de los tres ejemplares, para tratar de avanzar en la resolución de las dudas anteriores.

\section{Estudio material de los ejemplares conservados de 90DC}

Los catálogos de incunables coinciden en señalar la existencia de tres ejemplares de 90DC conservados respectivamente en la Real Biblioteca de El Escorial (BREsc. 32-V-19 $\left(3^{\circ}\right)$ ), en la Biblioteca General Universitaria de la Universidad de Zaragoza (BUZar I 84) y en la Biblioteca de la Real Academia Española (RAE I 42) ${ }^{29}$.

\section{Real Biblioteca de El Escorial [BREsc. 32-V-19 (3')]}

El ejemplar conservado en la Real Biblioteca de El Escorial es, con mucha diferencia, el mejor conservado. Está encuadernado en cuero con quirografías que siguen los márgenes en paralelo y enmarcan el sello de El Escorial que figura en el centro; los lomos están reforzados, si bien presentan algunas señales mínimas de rotura y las tapas casi sueltas. El tamaño de la encuadernación es de 140x200 mm; el papel interior mide 133×190 mm con señal clara de guillotinado para la encuadernación.

Forma parte de un facticio, con dos signaturas anteriores: VII Z 20 y IV Z 20; el número 20 de ambas aparece en el filo dorado del lado exterior de las hojas, según el almacenamiento habitual de la Biblioteca de El Escorial. Por ello, todo indica que el ejemplar se incorporó a la biblioteca ya encuadernado y con la configuración del facticio que mantiene en la actualidad.

Tal como hemos dicho arriba, su estado de conservación es óptimo, sin restauraciones, ni perforaciones, ni roturas; apenas presenta alguna pequeña marca de humedad y mínimas marcas de uso en los bordes. Apenas presenta marginalia de los usuarios del ejemplar; estos se limitan a marcas de referencia y una indicación manuscrita de tema en la h. 23v: «cordura / codicia».

El facticio está formado por las obras siguientes: Glosa de las coplas del Revulgo fecha por Fernando de Pulgar, Letra de Fernando de Pulgar de los males de la vejez, 90DC (vide supra) y Ars moriendi. El facticio así

\footnotetext{
${ }^{28}$ Se trata a todas luces del ejemplar más accesible al encontrarse digitalizado. [En línea]. Enlace: $<$ http://zaguan.unizar.es/record/375> [Consulta: 02/02/2020].

${ }^{29}$ Hemos seguido en la enumeración el orden de importancia para la edición crítica establecido por Sánchez López, art. cit., pp. XCV-XCVII, debido al estado de conservación de cada uno de ellos, como se verá.
} 
constituido, además del estado de los ejemplares contenidos en él, manifiesta la finalidad con la que se realizó, así como el perfil del destinatario inicial de la confección. La obra tiene un claro carácter moralizante y consolatorio ante los males de la vejez y la muerte; por ello, todo hace pensar que se trata de un ejemplar destinado a la lectura por parte de quien ya ha alcanzado la madurez y se encuentra en el tramo final de sus días, si bien no hemos localizado referencias a su posible poseedor o poseedores. Una función completamente diferente de la de los otros dos ejemplares, como veremos a continuación.

\section{Biblioteca General Universitaria de Zaragoza [BUZar I 84]}

El ejemplar de la Biblioteca Universitaria de Zaragoza está encuadernado en pergamino, con trencillas para el cierre, y con medidas de 140 × $200 \mathrm{~mm}$. Se encuentra en buen estado a pesar de las marcas de uso que presenta y las hojas no han sido guillotinadas. La encuadernación tiene una decoración muy simple de doble margen a lo largo de todos los laterales, tanto en la delantera como en la trasera del ejemplar. El cosido es muy básico y presenta numerosas páginas a punto de desprenderse.

Hay una marca en la guarda, en su parte central, muy borrosa: CATHON [...]. El deterioro la hace ilegible y probablemente contendría una signatura antigua. El interior del encuadernado contiene la signatura actual del ejemplar. Aparecen en la portada otras signaturas: «I 291 84» y «13829»; a plumilla se ha incluido en $1 \mathrm{r}$ «1.920»; en 48v se hace referencia a un posible poseedor: «Resmas $\mathrm{D}^{\circ}$. D. Jorge 133 año $1735 »$. Además de los sellos de la Biblioteca de la Universidad de Zaragoza, aparece en tres ocasiones (9r, 20r y 41r) la siguiente abreviatura: B.D.L.O.L.D.Z. Quizá puede identificarse con alguno de los poseedores del ejemplar, pero no hemos sido capaces de desarrollarla adecuadamente.

El ejemplar se encuentra en la actualidad en buen estado de conservación, ya que se han frenado los tres principales procesos de maculatura que presentaba:

1. Humedad: conserva restos de grandes manchas en las zonas centrales que incluso llegan a afectar la visualización de alguna de las filigranas ${ }^{30}$.

2. Polilla: sólo aparecen restos de xilófagos al comienzo del ejemplar; se ha detenido el proceso y se mantiene la pequeña maculatura que no ha precisado de reparación.

\footnotetext{
${ }^{30}$ Véase infra el apartado correspondiente a las filigranas en el estudio de la edición.
} 
3. Manchas ferruginosas: aparecen con frecuencia en el ejemplar manchas de tinta, alguna de las cuales ha producido algún deterioro menor en el papel. Ninguna de ellas parece poder relacionarse con la tinta empleada en la impresión o imputable a dicho proceso; más bien son producto de las anotaciones, marcas de referencia y marginalia que se han incluido con posterioridad, realizadas por no menos de tres manos diferentes y de carácter claramente escolar.

Al hilo de lo apuntado al final, hay señales de uso de lectores sucesivos, que han dejado marcadas las páginas al apoyarse en ellas para escribir sobre otro papel; incluso en la última página hay una marca de lo que parece ser un sello muy elaborado, que ha quedado marcado al apoyarlo sobre el ejemplar. Sin embargo, todas estas marcas y el sello son imposibles de transcribir sin dañar el ejemplar. En cualquier caso, denotan un uso frecuente con carácter, como decíamos, escolar.

A pesar de que no se hace referencia a ello en los catálogos, el ejemplar, como ya señaló Sánchez López ${ }^{31}$, presenta la mutilación de una hoja tras $6 \mathrm{v}^{32}$; es decir, en relación con el completo ejemplar de El Escorial, éste carece de la hoja 7. Esta mutilación provoca la pérdida de las glosas a los monósticos 25 a 30 (25 libros lege; 26 quod legeris memento; 27 litteras disce; 28 liberos erudi; 29 benefacito bonis; 30 blandus esto), si bien este último conserva la segunda redondilla; el corte limpio y la unidad temática de los monósticos 25-28 en torno al valor de los libros y el aprendizaje de las letras hace pensar en la intencionalidad de la mutilación, sin que pueda asegurarse.

Finalmente, frente al ejemplar de El Escorial, éste no presenta indicio alguno de haber formado parte de un facticio. Por todo lo apuntado, nos inclinamos a pensar que se trata de un ejemplar independiente con un amplio uso escolar.

\section{Biblioteca de la Real Academia Española [RAE I 42]}

La encuadernación en pergamino de este ejemplar es muy similar a la del anterior de la Universidad de Zaragoza, con la única diferencia de carecer de toda decoración. Del mismo tamaño, 140x200 mm, se encuentra en buen estado con ligeras marcas de uso. En el recto la guarda inicial una mano probablemente del siglo XVIII glosa el título de la obra y lo rubrica (ilegible); en el verso de la misma aparece a modo rúbrica también las iniciales $J G^{a} M^{a}$,

\footnotetext{
${ }^{31}$ Sánchez López, ob. cit., p. XCV.

${ }^{32}$ No hay muestra de que ésta haya sido arrancada, sino que se ha procedido a un corte limpio, sin que se pueda saber se ha practicado con posterioridad al deterioro completo de la hoja o directamente. 
que podrían responder a un poseedor o bibliotecario. El cosido y engomado, también equivalentes al ejemplar anterior, presentan signos de deterioro por el uso. En la guarda final del ejemplar una mano ha escrito:

$$
\begin{aligned}
& 1715 \\
& \hline 1467 \\
& \hline 0358 \\
& \hline 1715
\end{aligned}
$$

Se trata de un ejercicio de matemáticas básicas para el que se ha aprovechado un espacio en blanco.

El ejemplar presenta dos signaturas antiguas (o números de registro): R.68, tachado; y R 89.909. También tiene un ex libris antiguo de la RAE, pegado:

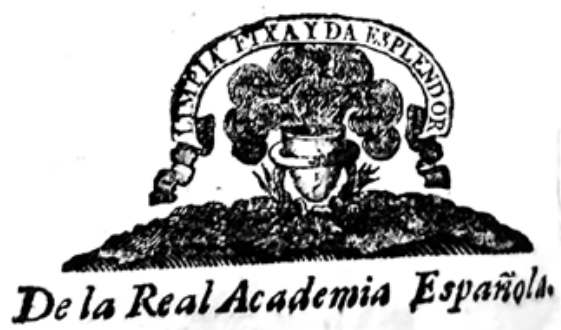

Dentro del ejemplar la encuadernación se encuentra muy deteriorada, con graves signos de humedad (paralizados en la actualidad) en la parte central, junto al engomado, más que probablemente provocados por la cinta marcadora incluida en la encuadernación. El papel refleja señales del uso de lectores sucesivos que no guardan relación con el contenido e incluso carecen de sentido, pudiendo calificarse de divertimentos de escolar; del mismo modo que alguno de dichos lectores se entretuvo dibujando la marca de agua principal $^{33}$ :
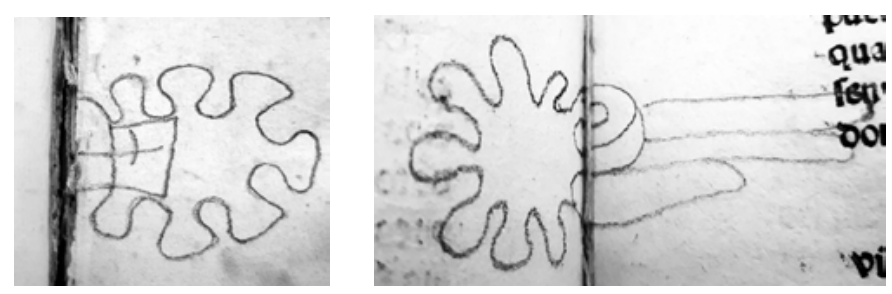

${ }^{33}$ Las reproducciones incluidas en este trabajo han sido realizadas por el autor con permiso de Servicio de Biblioteca de la R.A.E. 
La mutilación más grave de este ejemplar consiste en la pérdida de las 4 primeras hojas $(1 \mathrm{r}-4 \mathrm{v})$. No obstante, la encuadernación independiente actual se realizó ya con el ejemplar mutilado, toda vez que en el margen inferior de la h. 5r se ha escrito a plumilla lo siguiente: «Esta es la traducción delas sentencias de $\mathrm{Ca} /$ tón echa por el Maestro Martín Garcias / [...] siguese la Coronación de Diego Iñiguez que es [...]». A lo que sigue en $5 \mathrm{v}$ :

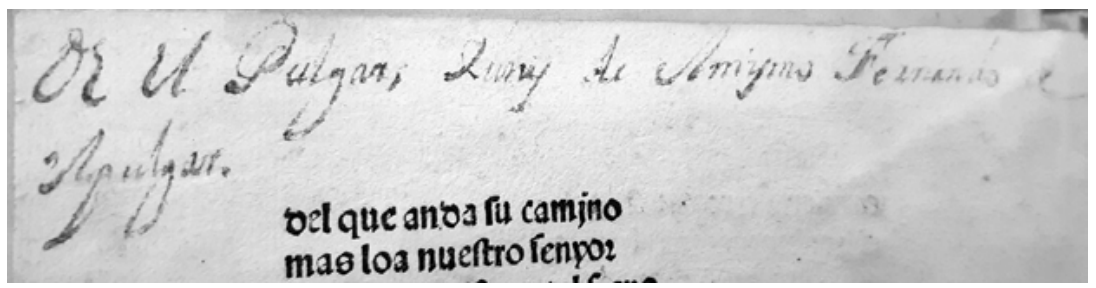

Todo ello parece indicar que, con anterioridad al estado en el que se conserva en la actualidad, este ejemplar constituyó un facticio junto con al menos dos obras de Fernando del Pulgar, coincidiendo en ello parcialmente con el ejemplar de El Escorial.

En cualquier caso, el ejemplar del que hablamos tuvo un uso marcadamente escolar en un primer momento, posteriormente pudo ser encuadernado en un facticio, y finalmente ingresar en la Biblioteca de la R.A.E. como ejemplar independiente.

\section{Materialidad y tipografía del pliego incunable 90DC}

El estudio de los tres ejemplares, a pesar de las diferencias asociadas a sus vicisitudes posteriores, permite concluir, como ya hizo Sánchez López ${ }^{34}$, lo siguiente: «Del análisis comparativo de los respectivos textos, así como de los rasgos tipográficos, puede deducirse que los tres ejemplares pertenecen a la misma edición (probablemente, la princeps)», $\mathrm{y}$, al parecer, la única.

La edición, cuya principal incógnita es el lugar de impresión, la fecha y el impresor, presenta un formato de doblado en $4^{\circ}$. La estructura colacional corresponde a 6 cuadernos de pliegos conjugados $\left(\mathrm{A}-\mathrm{F}^{8}\right)$ y, por tanto, es una edición de 48 hojas. Presenta un peculiar modelo de signaturas de cuaderno, en el que no se numeran las hojas, sino el cuaderno y cada uno de los pliegos conjugados, según el modelo Ai y Aii, donde Ai es el pliego externo y Aii el interno.

${ }^{34}$ Sánchez López, ob. cit., p. XCV. 
Hemos identificado en todos los ejemplares las mismas filigranas, que ocupan sistemáticamente la posición central de cada pliego; por ejemplo, en A, que corresponde a las hojas 1-8, las filigranas aparecen repartidas simétricamente en las hojas 2 y 7 , que corresponden al pliego Ai, y en las hojas 4-5, correspondientes al pliego Aii. Esta disposición se repite en todos los cuadernos de los ejemplares. En Ai la marca de agua utiliza el motivo de las tenazas $\left(\mathrm{N} 15^{35}\right)$ :

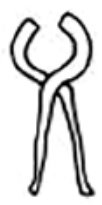

El resto de los cuadernillos muestran «mano jurando con guantelete de siete lengüetas» (A13/2/6) de la que Filigranas Hispánicas ofrece dos ejemplos:

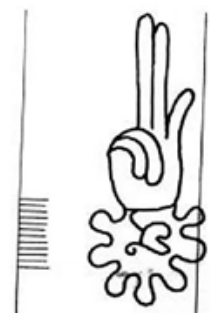

001653A

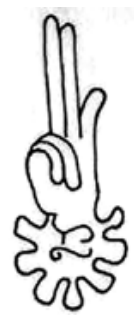

$0012472 \mathrm{~A}$

A tenor de las bases consultadas, se trata en ambos casos de filigranas empleadas en la fabricación de papel en la península ibérica, ya que N15 no aparece en los repertorios de marcas de agua europeos en las fechas de edición de 90DC, y A13/2/6 no lo hace en ningún caso ${ }^{36}$.

La ausencia de pie de imprenta en los ejemplares de 90DC, como ya hemos dicho, ha propiciado tres propuestas: (I) Enrique Mayer de Toulouse; (II) el denominado «Impresor del Catón»; y (III) la imprenta de los Hurus o de su círculo cercano. La primera de ellas es la que aparece sin excepción en las tres bibliotecas que albergan los ejemplares, por más que alguna de ellas

\footnotetext{
${ }^{35}$ Filigranas Hispánicas, Instituto del Patrimonio Cultural de España. [En línea]. Enlace: $<$ https:// www.mecd.es/filigranas/buscador_init> [Consulta: 07/02/2020]. No aparece este motivo en el rango temporal de 1450-1500 en el que hay que datar 90DC. Véase Bernstein-The Memory of Paper. [En línea]. Enlace: <http://www.memoryofpaper.eu/BernsteinPortal/appl_start.disp\#> [Consulta: 07/02/2020]. Es una obviedad indicar que en RAE I 42 sólo se conserva la segunda parte de esta filigrana.

${ }^{36} \mathrm{Como}$ indicamos en la nota anterior, hemos ampliado el rango cronológico de la búsqueda al objeto de asegurar nuestra afirmación.
} 
manifieste las dudas al respecto. En este sentido, al igual que los tipos de imprenta condujeron a que Vindel identificara con la misma imprenta la $E x$ positio super summulis Petro Hispani de Juan Versor ${ }^{37}$, hemos considerado oportuno cotejar la tipografía con el ejemplar de Enrique Mayer, Expositio Hymnorum (BUZar I 279-5), y el de Ars moriendi (BREsc. 32-V-19 (4º), impresa por Pablo Hurus y Juan Planck. El primero se incluye en un facticio latino, vide supra, en el que se incluyen los Disticha moralia, impresos por Juan Hurus aproximadamente entre 1488 y 1490 -las mismas fechas que se atribuyen a la Expositio Hymnorum-; la segunda nos interesa, puesto que, impresa unos años antes, entre 1480 y 1484 , forma parte del facticio en el que se incluye el ejemplar de El Escorial. Exponemos el cotejo de la tipografía de las mayúsculas en la siguiente tabla:

\begin{tabular}{|c|c|c|c|c|c|c|c|c|c|c|}
\hline 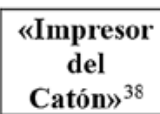 & 2 & $\boldsymbol{D}$ & $\mathfrak{C}$ & 20 & Eo & $y$ & & ID & $\mathfrak{3}$ & 2 \\
\hline $\begin{array}{l}\text { Expositio } \\
\text { Eymnorum }\end{array}$ & 匀 & 9 & $\mathcal{L}$ & $D$ & $\mathcal{E}$ & F & $B$ & 到 & 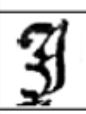 & \\
\hline 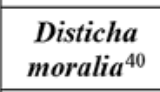 & 棲 & $1 \mathcal{B}$ & $\mathscr{E}$ & B & $\mathscr{E}$ & 5 & & Ib & 3 & \\
\hline $\begin{array}{l}\text { Ars } \\
\text { noriendit }\end{array}$ & $\mathcal{A}$ & IB & $\mathbb{L}$ & $D$ & IE & $\mathfrak{F}$ & $\mathfrak{B}$ & Ib & $\mathfrak{I}$ & \\
\hline
\end{tabular}

\begin{tabular}{|c|c|c|c|c|c|c|c|c|c|}
\hline $\begin{array}{c}\text { ppreseror } \\
\text { Cattony }\end{array}$ & $2 D$ & 1 & $\mathbb{B}$ & $D$ & 12 & $\mathbb{R}$ & $\mathfrak{S}$ & $\bar{x}$ & 2 \\
\hline Expositic & $\mathbb{4} \mathbb{2}$ & 算 & $D$ & $\beta$ & D. & $R$ & $\mathfrak{S}$ & 2 & 1 \\
\hline $\begin{array}{l}\text { Disticha } \\
\text { moralia }\end{array}$ & an & 7|Ai & 10 & 10 & $D$ & $\pi R$ & $\mathfrak{S}_{1}$ & 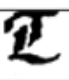 & bi \\
\hline$A r$ & $\mathbb{D A}$ & 调 & 10 & $p$ & $\theta$ & $\mathbb{R} R$ & $\Phi$ & $\mathfrak{Z}$ & 74 \\
\hline
\end{tabular}

Si atendemos a la comparación de $<\mathrm{M}>$, con doble trazo central y doble línea oblicua ascendente a la derecha ${ }^{42}$, la relación tipográfica entre el «Impresor del Catón» y Enrique Mayer podría parecer evidente. Ahora bien, la

\footnotetext{
${ }^{37}$ Vindel, ob. cit. p. XxvIII.

${ }^{38}$ Procedemos a reproducir los tipos, tomándolos de la digitalización de BUZar I 84. [En línea]. Enlace: $<$ https://zaguan.unizar.es/record/375/files/I_084.pdf > [Consulta: 08/02/2020].

${ }^{39}$ [En línea]. Enlace: BUZar I 279-4 < https://zaguan.unizar.es/record/344/files/I_279.pdf> [Consulta: 08/02/2020].

${ }^{40}$ La obra, BUZar I 279-3, se encuentra en la misma digitalización indicada en la nota anterior.

${ }^{41}$ Tipo 1:104G, identificado en GW02593. [En línea]. Enlace: <https://tw.staatsbibliothek-berlin.de/ ma12011> [Consulta: 08/02/2020].

${ }^{42} \mathrm{Si}$ bien un ligero trazo en la parte superior izquierda diferencia los tipos.
} 
comparación del resto de los tipos de mayúscula nos aleja de tal conclusión. Efectivamente, sólo un tipo tan poco marcado como $<\mathrm{S}>$ permite establecer esta misma relación, pero, no obstante, la semejanza también es notable con Disticha moralia y con Ars moriendi; también $<\mathrm{U}>$ los pone en relación, debido al doble trazo oblicuo interno ascendente, mas también lo hace con Disticha moralia. Las restantes confluencias se agrupan entre «impresor del Catón» y Disticha moralia, $<\mathrm{A}, \mathrm{H}, \mathrm{I}, \mathrm{L}, \mathrm{P}>$, y la agrupación de estos dos últimos con Ars moriendi, $<\mathrm{B}, \mathrm{C}, \mathrm{D}, \mathrm{E}^{43}, \mathrm{~N}, \mathrm{O}, \mathrm{Q}, \mathrm{R}, \mathrm{T}>^{44}$. Todo ello permite establecer una característica común a la tipografía de «impresor del Catón», Disticha moralia y Ars moriendi, que escasamente se refleja en la Expositio hymnorum: la tendencia al empleo de doble trazo en la parte izquierda de los tipos. Dicho de otro modo, dicha característica, compartida con el taller de Hurus o de Hurus-Planck, es apenas utilizada por Mayer.

\section{Conclusiones}

La obra de Martín García Puyazuelo, La ética de Catón, presentaba la incógnita principal sobre el taller de impresión, el lugar de ésta y la data. El estudio de los ejemplares conservados, especialmente de las filigranas y de la tipografía, ha permitido apuntar algunas conclusiones.

En primer lugar, por más que sea necesario seguir profundizando en esta línea de trabajo, tanto el carácter claramente hispano de las marcas de agua del papel utilizado, como la agrupación de semejanzas en el estudio de la tipología de las mayúsculas, nos hace concluir que la posibilidad de que la edición se haya realizado en el taller tolosano de Enrique Mayer debe considerarse remoto, salvo que se aporten otras evidencias. Así mismo, todas las comparaciones realizadas permiten afirmar que la data reconocida más habitualmente, $c$. 1490, debería precisarse; sugerimos ampliar la horquilla cronológica de la impresión entre 1480 y 1500 , si bien con una clara tendencia a que se produjera en la segunda mitad de la década de los 80 del siglo Xv.

En segundo lugar, la relación que permite establecer la tipografía con el círculo impresor de los Hurus, círculo intelectual con el que se relacionó y con el que compartió intereses literarios y culturales, se compadece bien con la biografía de Martín García. Es por ello que, si bien no podemos afirmar con rotundidad que la obra saliera de los talleres de dichos impresores, todo

\footnotetext{
${ }^{43}$ En este caso con alguna duda por el trazo descendente inferior sin posterior ascenso.

${ }^{44}$ No hemos incluido en esta enumeración $<\mathrm{G}>$ por no disponer de la posibilidad de cotejar los cuatro incunables; $\mathrm{ni}<\mathrm{F}>$, donde la desemejanza entre los cuatro es evidente.
} 
apunta a que la edición fue llevada a cabo en Zaragoza, si no por ellos, por algún impresor relacionado con el citado círculo.

Finalmente, debemos indicar que por razones comerciales, educativas y culturales los Disticha Catonis fueron una preocupación del mencionado círculo zaragozano. En este trabajo hemos mencionado tres obras, los Disticha moralia (1488-1490) sólo con texto latino, la traducción de arte menor de Martín García (c. 1490) y la traducción de arte mayor de Gonzalo García de Santa María (1493), estas dos últimas conteniendo también el texto latino. Dadas las relaciones conocidas entre los responsables de estas ediciones cuesta trabajo pensar que no guarden relación entre ellas, o, dada la proximidad en el tiempo y en el espacio en su producción, cabe preguntarse la relación que mantienen. Si tenemos presente que el elemento común a los tres incunables es el texto latino incluido en ellos, pensamos que su comparación puede arrojar algún tipo de luz a este respecto. Junto a ello, por supuesto, el análisis de las preocupaciones culturales que dominaron el círculo zaragozano que en el siglo Xv se aglutinó en torno a los impresores, muy especialmente los Hurus.

Recibido: 9/03/2020

Aceptado: 15/04/2020 


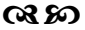

El PLIEGO POÉTICO INCUNABLE 90DC: MATERIALIDAD Y ADSCRIPCIÓN TIPOGRÁFICA

RESUMEN: El pliego poético incunable 90DC tiene varias incógnitas no resueltas: la datación, el lugar de impresión y el taller en el que fue confeccionado. Este trabajo realiza la autopsia de los tres ejemplares conservados en Zaragoza, Madrid y El Escorial, compara la tipografía y analiza las marcas de agua del papel. La conclusión es que la impresión tuvo que realizarse en la ciudad de Zaragoza, en el círculo de los hermanos Hurus.

Palabras Clave: Disticha Catonis. Martín Puyazuelo. Incunable. Hurus. Tipografía. Filigrana.

THE 90DC INCUNABULUM POETIC SHEET:

MATERIAL ASPECTS AND TYPOGRAPHICAL STUDY

ABSTRACT: The 90DC incunable poetic sheet has several unresolved unknowns: the dating, the printing place and the workshop in which it was made. This work does the autopsy of the three copies preserved in Zaragoza, Madrid and El Escorial, compares the typography and analyzes the watermarks of the paper. The conclusion is that the impression had to be made in the city of Zaragoza, in a circle of the Hurus brothers.

Keywords: Disticha Catonis. Martín Puyazuelo. Incunabulum. Hurus. Typography. Watermark. 